\title{
Nuclear fusion and renewable energy forms: Are they compatible?
}

\author{
Thomas Hamacher ${ }^{\mathrm{a}}$, Matthias Huber ${ }^{\mathrm{a}}$, Johannes Dorfner ${ }^{\mathrm{a}}$, Katrin Schaber ${ }^{\mathrm{a}}$, Alex M. Bradshaw ${ }^{\mathrm{b}}$ \\ ${ }^{a}$ Lehrstuhl für Energiewirtchaft und Anwendungstechnik der Technischen Universität München, \\ Arcissstrasse 21, 80333 München, Germany \\ ${ }^{b}$ Max-Planck-Institut für Plasmaphysik, Association IPP-Euratom, Boltzmannstr. 2, 85741Garching and \\ Fritz-Haber-Institut der Max-Planck-Gesellschaft, Faradayweg 4-6, 14195 Berlin, Germany
}

\begin{abstract}
Nuclear fusion can be considered as a base-load power plant technology: High investment costs and limited operational flexibility require continuous operation. Wind and solar, on the other hand, as the putative main pillars of a future renewable energy system, are intermittent power sources. The resulting variations that occur on many different time scales require at first sight a rather flexible back-up system to balance this stochastic behavior. Fusion would appear not to be well suited for this task. The situation changes, however, if a large-scale renewable energy system is envisaged based on a transnational, or even transcontinental power grid. The present paper discusses a possible European power system in the year 2050 and beyond. A high percentage share of renewable energies and a strong power grid spanning the whole of Europe and involving neighboring countries, in particular those in North Africa, are assumed. The linear programming model URBS is used to describe the power system. The model optimizes the overall system costs and simulates power plant operation with an hourly resolution for one whole year. The geographical resolution is at least at the country level. The renewable technologies are modeled first on a more local level and then summed together at the country or regional level. The results indicate that the smoothing effects of the large-scale power grid transform the intermittent renewable supply, which is then more compatible with base-load power plants such as fusion reactors.
\end{abstract}

Keywords: Fusion power plant, renewable energy forms, electricity production, intermittency, transcontinental power grid

\section{Introduction}

Fusion is a potential technique for large-scale electrical power generation in a sustainable way, but is still under development. Most strategies foresee that at least two major advances have to be made before commercially viable fusion plants are available. The first step is the realization of the international ITER experiment and the second the construction of a demonstration power plant, usually referred to as DEMO. Parallel to this program, there also has to be considerable development in technology and materials research. ITER is at present under construction in Cadarache, France; the device is expected to be completed in 2019 and the first fusion-relevant plasmas will be produced in 2025. Design and construction of DEMO could in principle start earlier, but final design decisions require that data from ITER on burning plasmas (i.e. deuterium-tritium plasmas that produce more energy from the fusion reaction than that required for heating the plasma) are available. It is therefore unlikely that commercial fusion power plants will be available before 2050 .

What will the electrical power system look like in 2050? Will fusion be able to penetrate the market? These questions can hardly be answered without making many assumptions, some of which can certainly be challenged. However, the question is not to forecast the exact penetration rate of fusion in forty years from now, but to show whether it still makes sense to go ahead with fusion research at a time when nuclear fission as an energy source is being called into question in many countries (the many positive features of fusion in comparison with fission notwithstanding). Answering these questions is thus important for making rational decisions today.

From many forecasts and projections we expect that by the year 2050 renewable energy forms will start to dominate the power sector. Investment costs for wind turbines, photovoltaic (PV) arrays and other renewable energy systems are expected to decrease as the result of technological development, mass production and other scaling effects. Fossil fuel costs are expected to rise and CO2-emissions will be strictly limited as part of worldwide measures to combat global warming. Moreover, the demand for electrical power is expected to increase. Drivers will be population increase and economic growth as well as a shift to electricity which may by then be the dominant final energy carrier.

Simple arguments suggest that fusion, with its high investment costs and rather limited operational flexibility, is not a suitable base-load technology in this situation because it is not compatible with intermittent renewable energy sources. Further, by the year 2050 the cost of electricity from renewable energies may have reached such a low level that it can no longer be challenged by fusion. 
In this paper we attempt to counter these arguments with the help of a power grid model which focuses on Europe and North Africa. Fusion is included in the model as a possible power source from 2050 onwards. A cost optimization process then decides which technologies are finally applied. The paper is organized as follows: In the next section we discuss probable future developments in electricity demand. In section 3 the formal Europe-North Africa power grid model is presented and the underlying data-base discussed. Finally, the results for four scenarios with fusion at various levels of investment are reported in Section 4.

\section{Future electricity consumption}

Energy savings and energy efficiency are - at least for developed countries - important ingredients in any energy strategy. The question is whether these efforts will actually lead to a decrease in electricity consumption. A final answer is unfortunately not possible due to the many uncertainties involved. In the past there has always been a strong correlation between economic growth and electricity consumption. The correlation is very strong for developed countries, while in developing countries there is a stronger dependence of primary energy demand on economic growth [1]. This shows that electricity gains importance as a final energy carrier with the economic development of a country. The correlation with economic performance also became visible during the financial crisis in 2009, which resulted in a significant drop in electricity consumption in many countries and halted the global increase at least for one year! The development of global electricity generation is shown in figure 1 . The plot shows that global electricity generation has increased on average by $3.6 \%$ annually in the last 22 years.

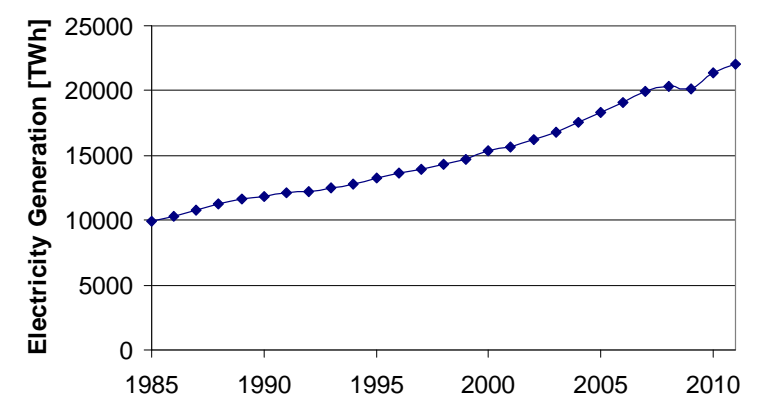

Fig.1: The development of the global electricity production in the last 25 years [2]. Source: BP.

Technology-based investigations also show that a continuing increase in global electricity consumption is rather likely. Electricity is expected to penetrate more final energy sectors. Prominent examples are heat pumps for domestic heating, electric vehicles in transport and advanced computing centers in the service sector. For the purposes of modeling in this paper we assume a slight increase of the electricity consumption in Europe but a steep increase in North Africa.

\section{The electricity model}

The electricity model is based on the model generator URBS [3], which was especially designed to describe energy systems with a high share of renewable energies. Investment decisions and power plant scheduling are the result of a cost minimization process. The objective function, which is minimized, includes all system costs including investment costs for power plants, transmission lines and storage plants as well as fuel and operation and maintenance costs. The investment costs were distributed by a conventional annuity method to each year of the plant life with an interest rate of $7 \%$. The system is optimized for the year 2050 .

A model of the European and North-African power system for the year 2050 was designed. The countries considered are depicted in the map of figure 2. Each is described as one node in the grid described by the model. Neighboring countries are connected by power lines. Europe and Middle East/North Africa (EUMENA) are linked in the same way. Compared to the present situation, a significant increase in the level of power transmission between different European countries is assumed possible.

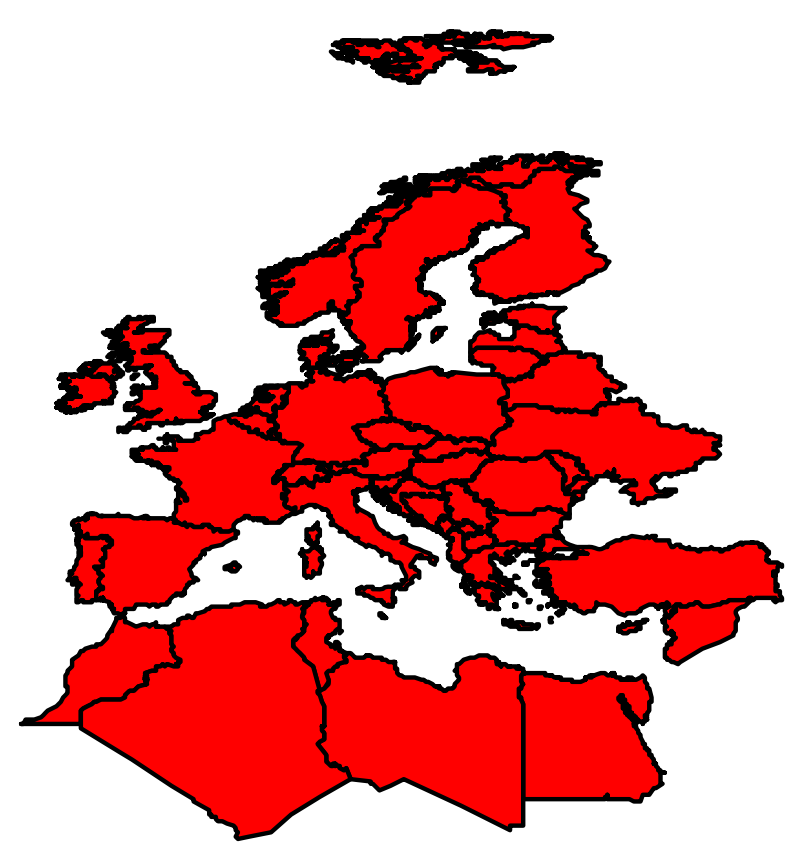

Fig.2: The countries in Europe and North Africa in the power system model.

The intermittent nature of renewable energies is described with the help of a data set, which includes the wind velocities and solar irradiation values for a typical year with hourly resolution. Wind velocities and solar irradiation data were taken from various sources. They are summarized in Ref. [4]. The relation between wind 
velocity and power output depends on the characteristics of the wind turbine. The same characteristics are assumed for all sites. In future, site-dependent characteristics will be taken into account. A similar procedure is applied for the other renewable energy technologies. A summary of the power output of the wind turbines can be found in figure 3. Summing over the geographically dispersed wind sites leads to a considerably smoothed supply curve (blue curve "EUMENA"). Most importantly, the capacity factor remains over 0.2 up to $8000 \mathrm{~h}$. This explains why wind plays such an important role in the results and why it fits quite well to conventional base load plants such as fusion.

Four scenarios are presented. In the first three the investment costs for the underlying fusion technology is varied.

\section{Fusion 1: $3000 € / \mathrm{kW}$}

\section{Fusion 2: $4500 € / \mathrm{kW}$}

\section{Fusion 3: $7500 € / \mathrm{kW}$}

In the fourth, "renewable" scenario fusion is not available (nor is "new build" fission, which might conceivably in 40 years be an alternative, even if this seems unlikely at present).

The other major assumptions are as follows:

Electricity demand in Europe: $\quad 3000$ TWh/a

Electricity demand in Turkey: 509 TWh/a

Electricity demand in MENA: $\quad 970$ TWh/a

Limit for CO2 emissions in Europe, which is a $95 \%$ reduction compared to 1990: $143 \mathrm{Mt} / \mathrm{a}$

The major characteristics of the technologies are summarized in table 1. Further information can be found in the report of Huber et al [5].

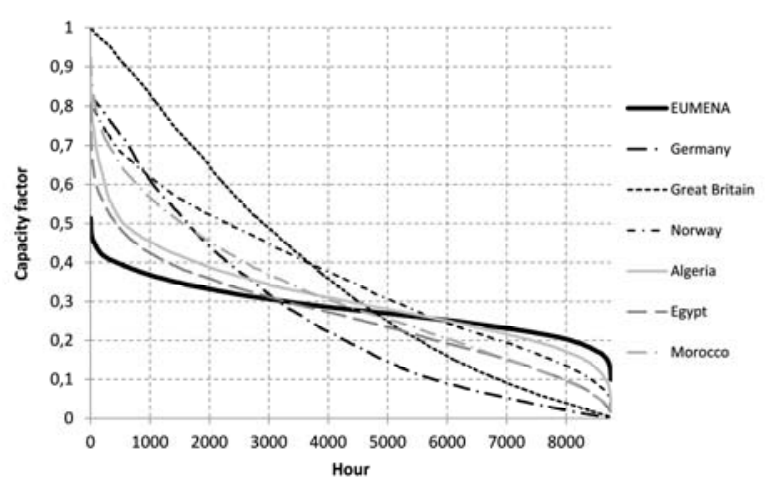

Fig.3 Annual supply curve for on-shore wind power in various European and North-African countries. The blue EUMENA curve is the sum of all sites.
Only those pump storage options at present existing, as well as planned new plants are assumed to be available. This is a point which will need more detailed investigation in future. The detailed assumptions used in, and the results from, this study can be found in [5]. The results presented here are in part preliminary and require further refinement. This is particularly true for the wind data.

\section{Results}

The major results are presented in figure 4. In scenario "Fusion 1" with rather moderate investment costs, fusion would dominate with more than $50 \%$ the electricity production. The average electricity price would be down by 2 cents/kWh compared to the other scenarios. The extension of the power grid would be rather moderate. As perhaps expected, the share of fusion decreases with increasing fusion investment costs. However, even with very high investment costs, fusion would contribute $15 \%$ to overall electricity production. In this scenario $50 \%$ of the production is contributed by intermittent sources, mainly wind.

In the fourth, "renewable" scenario only gas and renewable technologies supply electricity. Gas supplies less than $10 \%$ of the overall power. Remarkable is the dominant role of wind power. Wind supplies roughly 50 $\%$ of the electricity. The dominant role of wind is stable against sensitivity variations. No other renewable technology can gain a similar importance, even if costs are reduced considerably. Technologies using direct solar radiation supply in all scenarios less than $10 \%$ of the overall production. Possible new technologies such as ocean power were not considered. The high share of renewable energies requires a strong reinforcement of the power connections within Europe and between Europe and North Africa.

The role of natural gas as back-up is still rather important. Even very efficient combined-cycle power plants will still be able to react quickly to dynamic load changes. The gas needs, however, to be supplied from somewhere and the easily accessible resources are likely to be reduced considerably during the course of the $21^{\text {st }}$ century. Therefore it is rather important to note that in "Fusion 1" the gas demand is down by a factor 4 compared to the "renewable" scenario.

The central question is whether it is possible for fusion as a base-load technology to coexist with intermittent renewable technologies. In the past the power system was organized in three tiers: base-load as well as middle and peak loads. Base-load plants supplied power day and night, while middle load operated only during the day and peak load only during the lunchtime period. The advent of intermittent renewable technologies altered the concept. These were considered to be so-called must-run plants, which supply electricity whenever the weather situation provides adequate wind velocities or sufficient solar radiation. The must-run plants need to be backed up by plants capable of 
continuous operation. This is actually still the current philosophy, since no major storage options are available, nor can a transcontinental power grid provide smoothing effects. As can be seen in fig 3, smoothing effects due to the existence of a transcontinental power grid transform the wind power supply into a system which actually looks more like former base-load or middle-load power plants.

\section{Conclusion and Outlook}

Global research efforts make it likely that nuclear fusion will be commercially available by the middle of the $21^{\text {st }}$ century. The present study shows that fusion and renewable technologies can co-exist with varying market shares without running into severe system incompatibilities. In particular, the existence of a transcontinental power grid can, at least in part, smooth out the supply variations from renewable energy sources. Moreover, it becomes clear that fusion and renewables in combination can even reduce the remaining natural gas demand and are therefore a good mix on the path to a CO2-free electrical power system. The results presented are based on an economic rationale only. Other considerations, such as those based on political decisions, or lack of public acceptance might change the picture.

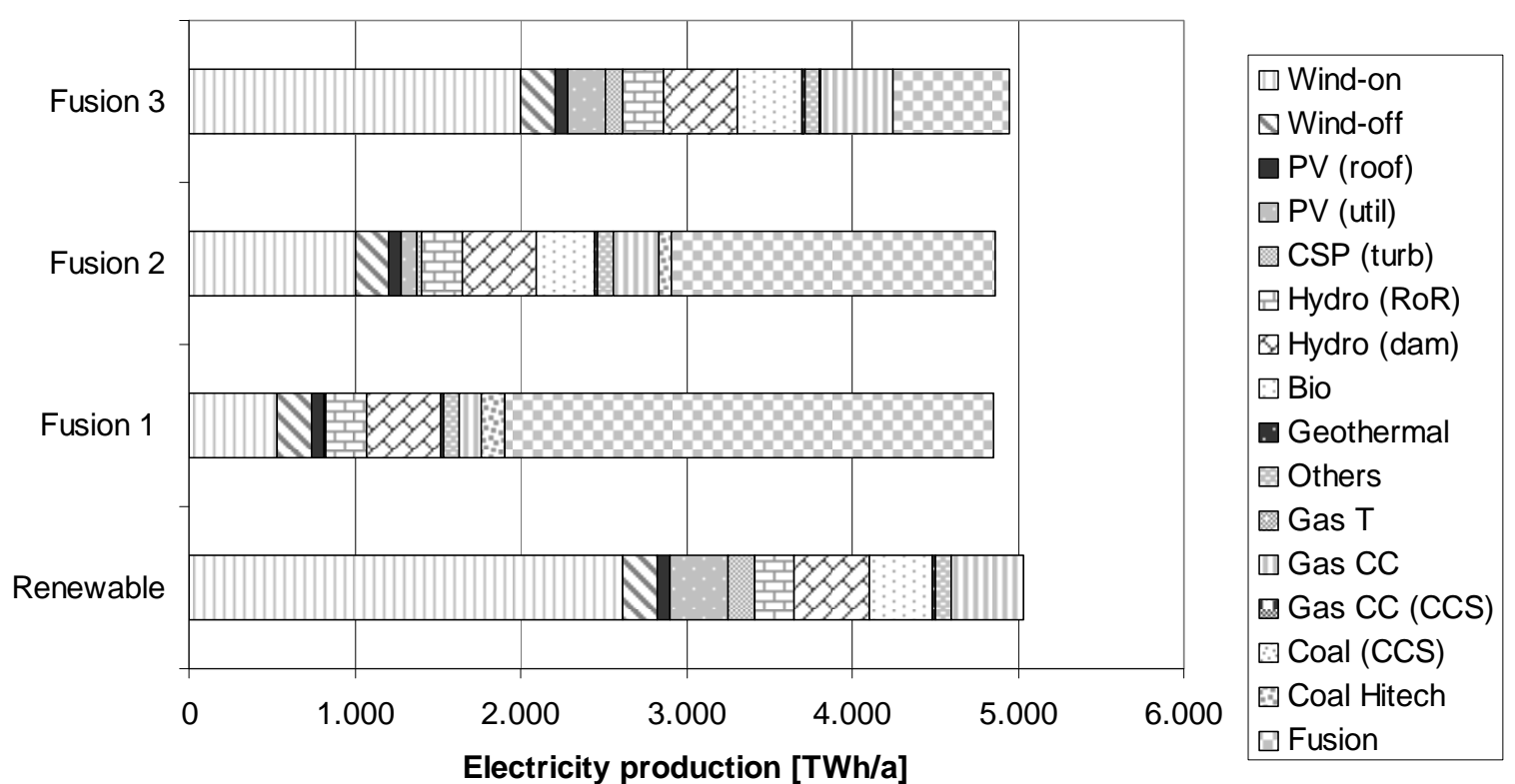

Fig.4 Electricity production in the four scenarios.

\section{Tables}

Table 1: Characteristics of major renewable technologies; for biomass a variable cost of $4 € / \mathrm{kWh}$ is also assumed.

\begin{tabular}{llll}
\hline $\begin{array}{l}\text { Technolog } \\
\mathrm{y}\end{array}$ & $\begin{array}{l}\text { Investme } \\
\text { nt Cost }\end{array}$ & Fix Cost & Lifetime \\
\hline CCGT & $7 € / \mathrm{kW}]$ & {$[€ / \mathrm{kW}]$} & {$[\mathrm{a}]$} \\
\hline PV- & 1080 & 29 & 30 \\
rooftop & & & 25 \\
\hline PV- & 801 & 22 & 25 \\
utility & & & \\
Wind-on & 932 & 31 & 25 \\
Wind-off & 1495 & 60 & 20 \\
Biomass & 2450 & 80 & 25
\end{tabular}

\section{References}

[1] R. Ferguson, W. Wilkinson, R. Hill, Electricity use and economic development, Energy Policy 28 (2000) 923-934

[2] BP Statistical Review of World Energy, London, 2012

[3] N. Heitmann, Lösung energiewirtschaftlicher Probleme mit Hilfe linearer Programmierung, IPP Report 16/6, MaxPlanck Institute for Plasma Physics, Garching, Germany, 2005

[4] S. Bofinger, L. von Bremen, K. Knorr, K. Lesch, K. Rohrig, Y-M. Saint-Drenan, and M. Speckmann. Raumzeitliche Erzeugungsmuster von Wind- und Solarenergie in der UCTE-Region und deren Einfluss auf elektrische Transportnetze: Abschlussbericht für Siemens Zentraler Forschungsbereich. Institut für Solare Energieversorgungstechnik, ISET e.V., University of Kassel, Germany, 2008

[5] M. Huber, J. Dorfner, T. Hamacher, Electricity system optimization in the EUMENA region, TU Munich internal report, Lehrstuhl für Energiewirtschaft und Anwendungstechnik der Technischen Universität München, Germany, 2012 